\title{
8
}

\section{The Impacts of Land Use Change on Biodiversity in Australia}

\author{
John Neldner
}

\section{Key Points}

- Habitat loss through land clearing is a leading threatening process of terrestrial biodiversity.

- Increasing intensity of landscape change will increase the loss of wildlife, with a rapid loss once native vegetation falls below 30 per cent.

- As well as the direct impacts on biota of land clearing, the associated fragmentation and habitat modification exacerbates impacts, and there is often an extended extinction debt to be realised.

- Potential economic returns for individuals frequently drives landscape change, whereas the public good from biodiversity services, and the cost of losing these services, are rarely accounted for.

- Legislative and incentive-based approaches are necessary for landscape sustainability.

\section{Introduction}

Biodiversity includes all species of organisms, both common and rare. International biodiversity conventions have been signed by many countries. The reasons for preserving biodiversity fall into three general 
categories: ethics, economics and human welfare (Covacevich, 1995). Regional landscape change can be driven by changes in human population, economic and cultural values, government policy and technology. The magnitude of these changes may be tempered by environmental constraints, but frequently economics is the primary driver (Seabrook, McAlpine \& Fensham, 2006).

\section{Intensity of Land Use}

Land uses can be regarded as intensive or extensive, depending on the degree to which they modify the environment. More intensive land uses result in a greater share of resources and energy flowing to human uses, leaving less to sustain other species. Hence, different land uses have varying impacts on the biodiversity of an area. The impact on biodiversity increases with the intensity of land use, from no impact to more than 95 per cent loss of the mean species abundance (Taylor, Eber \& Toni, 2014). The loss of wildlife species from landscapes tends to occur when clearing exceeds 20 per cent of the landscape, and rapidly accelerates when less than 30 per cent of the native vegetation remains (McAlpine, Fensham \& Temple-Smith, 2002; Morgan, 2001). Cautioning against a simple threshold for all landscapes, Maron et al. (2012) have shown that actual thresholds for decline may be affected by landscape productivity and the natural cover of the vegetation. Land cover has been used as a surrogate for habitat for terrestrial biodiversity, and disturbed land cover represents a deleterious change in the habitat suitability (Graetz, Wilson $\&$ Campbell, 1995). Morgan (2001) mapped landscape health in Australia by integrating the state and trend in native vegetation extent, connectivity and condition, dryland salinity, hydrology, weeds, feral animals, threatened ecosystems and species. Broadly, Australia was divided into two zones: the intensive use zone, represented by large areas of fragmented land and significant areas of cropping and intensive domestic grazing, and the extensive use zone, where very little clearing had occurred and extensive grazing was the predominant land use. Thackway and Lesslie (2006) classified vegetation into six broad condition classes ranging from natural systems through to completely transformed environments. While these frameworks are useful tools for communicating the current condition and trend of vegetation and landscapes, Eyre, Fisher, Hunt and Kutt (2011) argued that they are a poor indicator of biodiversity persistence and trend, and that what is required is a comprehensive monitoring framework to measure biodiversity and driver indicators, both directly and indirectly. 


\section{Direct Effects on Biodiversity}

Land clearance is one of 16 threatening processes recognised for Australian terrestrial biodiversity under the Environment Protection and Biodiversity Conservation Act 1999 (EPBC), and is regarded as exerting one of the most intense impacts on biodiversity. Using accurate tree clearing mapping (Accad, Neldner, Wilson \& Niehus, 2001) and estimates of average densities of tree and vertebrate animal species in broad vegetation types, Cogger, Ford, Johnson, Holman and Butler (2003) conservatively estimated that, in the Brigalow Belt of Queensland, more than 112 million trees were cleared each year between 1997 and 1999. They further estimated that this resulted in the deaths of 1 million mammals, 5 million birds and 52 million reptiles. Not all these animals were killed directly by the clearing process—-some mobile species would have escaped to remnant vegetation; however, they would have soon perished from starvation or predation in these fully occupied and frequently fragmented and degraded habitats. McAlpine et al. (2002) estimated that a reduction in remnant vegetation to 30 per cent would result in the loss of 25-35 per cent of the vertebrate fauna; however, the full impact may take more than 100 years. While habitat loss is the primary impact of clearing on biota, the fragmentation and modification of the remaining habitat has a strong secondary deleterious effect (Haddad, Brudvig \& Clobert, 2015). Patch size and landscape connectivity have been shown to have a strong relationship with retained biodiversity (Bowen, McAlpine, House \& Smith, 2007).

\section{Indirect Effects}

The impact of vegetation clearance on biodiversity may take decades to become apparent (Cogger et al., 2003; McAlpine et al., 2002). Extinction debt works through local extinctions gradually becoming regional: eventually, the entire species is made extinct. In addition, immigration lag, in which small or isolated patches are slower to accumulate species, has been shown to result in 5 per cent fewer species after one year, and 15 per cent fewer species after 10 years (Haddad et al., 2015). The third process of degradation caused by fragmentation is ecosystem function debt. Haddad et al. (2015) recorded decreases in nutrient cycling and plant and consumer biomass of up to 80 per cent after 10 years in small fragments. It is difficult to measure these changes and disaggregate their 
causes, as frequently there are many interactions through processes such as habitat fragmentation and degradation, contact with non-native species and flow-on effects from outside the locality (e.g. extreme weather associated with climate change) that lead to decreased resilience.

Twelve threatening processes listed under the EPBC for terrestrial Australia are based on exotic plants (e.g. gamba grass, escaped garden plants and novel biota) or animals (e.g. rabbits, goats, foxes, cats, pigs, fire ants and cane toads), three are based on the effects of exotic diseases and one is based on a native species (i.e. noisy miner, Manorina melanocephala). Within the suite of species that occupies a given location, there may be some winners (increasers) who benefit from the new environmental conditions provided by clearing (e.g. large kangaroos), while other species will be losers (decreasers) or neutral (e.g. small woodland birds). Feral animals, such as cats and foxes, directly prey on Australian biota, while rabbits, goats and pigs degrade the landscape, consume native plants and directly compete with native herbivores for food. Exotic plants can outcompete native plants (e.g. linear declines in plant species richness as buffel grass cover increases) (Fensham, Wang \& Kilgour, 2015), or create conditions that transform landscapes and make them unfavourable for native species (e.g. gamba grass produces high biomass loads that encourages tree-killing hot fires in the tropical savannas). The clearing, or thinning, of vegetation may lead to a native species becoming a competitive excluder of other biodiversity; for example, yellow-throated miners dominating and excluding smaller birds (<53 grams) throughout 500,000 square kilometres of northern Australian rangelands (MacNally et al., 2014). The nonnative fungal disease Phytophthora cinnamomi has led to the degradation of biodiversity in the Western Australian heathlands, particularly affecting the family Proteaceae. Myrtle rust has a similar potential in the east-coast rainforests.

While land clearing causes a substantial loss of biodiversity, significant negative impacts can occur where only subtle land use change has been recorded. In Australia, the very high rate of land mammal extinction-10 per cent in the last 200 years-is most likely due to predation by feral cats and foxes and changed fire regimes (Woinarski, Burbidge \& Harrison, 2015). Large areas of intact vegetation in the extensive land use zone of northern Australia, and even in protected areas such as Kakadu National Park, are exhibiting dramatic mammal losses. To put this in perspective, in 1996, small mammals were captured in 89 per cent of quadrats in Kakadu National Park, compared to only 
35 per cent in the 2000 sampling. There is considerable interest in the reintroduction of the dingo as an apex predator to assist in the restoration of rangelands through controlling feral predators (Newsome et al., 2015).

\section{Assessing and Measuring Impacts}

We can understand the changes to biodiversity through inventories and comparison of analogous ecosystems in different condition states or, more thoroughly, through long-term monitoring of ecosystems undergoing land use change. Robust assessments of the condition of the Australian environment will only be possible if a representative sample of ecosystems is monitored using stratified and replicated plots over the long term (Eyre et al., 2011; Lindenmayer, Burns \& Tennant, 2015). The monitoring of key components of ecosystems needs to commence as soon as possible and continue for at least several decades to provide information to guide ecologically sustainable development that retains biodiversity. Listing species—and, increasingly, ecological communities—as threatened has been seen as a gauge of the impact of land use change on biodiversity; however, this is an uncertain gauge, as we have very limited knowledge for many species. The International Union for Conservation of Nature (2012) criteria for assessment of threatened species examines population decrease 'over the last 10 years or three generations, whichever is the longer time period' to determine decline and threat. In many cases, the major reduction in habitat and species population occurred many years earlier; consequently, the assessment is based on decline within the depleted population, rather than on what the species population would have been prior to clearing. For example, the brigalow ecological community and many brigalow-dominated regional ecosystems have experienced huge losses of remnant habitat and have been listed as endangered under the EPBC and Queensland's Vegetation Management Act 1999 (VMA); however, the number of listed threatened or near-threatened species living under Queensland's Nature Conservation Act 1992 (NCA) in these areas is low_only eight species of reptiles, two mammals, six birds, one butterfly and three vascular plants (see Figure 8.1). Hence, the threatened species list is a blunt indicator of the status of individual species as compared to preEuropean populations, and of landscape change impacts on biodiversity. 


\section{Ameliorating the Impacts? Can Biodiversity and Development Survive Together?}

While conservation within an expanded reserve system remains an important priority, many native fauna species occupy modified landscapes outside the formal reserve system. Further, the reality for agricultural landscapes suffering high levels of habitat loss and fragmentation is that the protection of remnant (i.e. not previously cleared) habitat alone will not be enough to achieve biodiversity conservation goals, and some form of landscape restoration will be necessary (Bowen et al., 2007).

Restoration of landscapes (e.g. rehabilitation plantings) can improve biodiversity values, but there may be a considerable lag before suitable habitat requirements are met; for example, hollows in large trees take more than 100 years to develop. Native woody plants can colonise extensive areas when there are social drivers, such as the change from traditional agriculture to rural amenity use, resulting in 1,800 hectares per decade becoming shrublands on low fertility soils in central Victoria since the 1960s (Geddes, Lunt, Smallbone \& Morgan, 2011). This old field succession, or natural regrowth, can be far more extensive than intentional plantings (Fensham \& Guymer, 2009).

Landscape change is driven by economic, demographic and cultural factors operating at a range of spatial and temporal scales, with the drive to maximise the return on an investment often being most important (Graetz et al., 1995; Seabrook et al., 2006). Since it is very difficult to control the economic market, governments attempt to exert influence through planning and regulation (and compliance) and, occasionally, through the use of incentives. The concept of ecosystem services and the market providing a positive incentive to retain values is potentially starting to occur through the carbon market; however, it is not operational for most biodiversity values and services (e.g. pollination from flying foxes). A price on carbon is driving land use changes globally, but the benefit to biodiversity depends on the planting methodology used (Carwardine et al., 2015; Fensham \& Guymer 2009). Other major political drivers, such the Carbon Farming Initiative and offsets policies, attempt to drive landscape change and compensate for biodiversity loss in development areas. Biodiverse plantings that attempt to restore pre-clearing vegetation by including a full suite of plant species and lifeforms will generally produce more biodiversity benefits, and be more resilient to climate variability 
and fire impacts (Dwyer, Fensham, Butler \& Buckley, 2009; Fensham \& Guymer, 2009). The biodiversity contained in rehabilitation depends on many factors, including the ability of species to move to the new habitat, soil and seasonal conditions to allow germination and follow-up management to allow successful establishment and reproduction for selfsustaining populations. Higher biodiversity benefits would be expected from restoration plantings in endangered ecological communities, habitats for threatened species and areas well connected to other natural vegetation (Carwardine et al., 2015; Munro et al., 2009).

\section{A Case Study of Brigalow Communities}

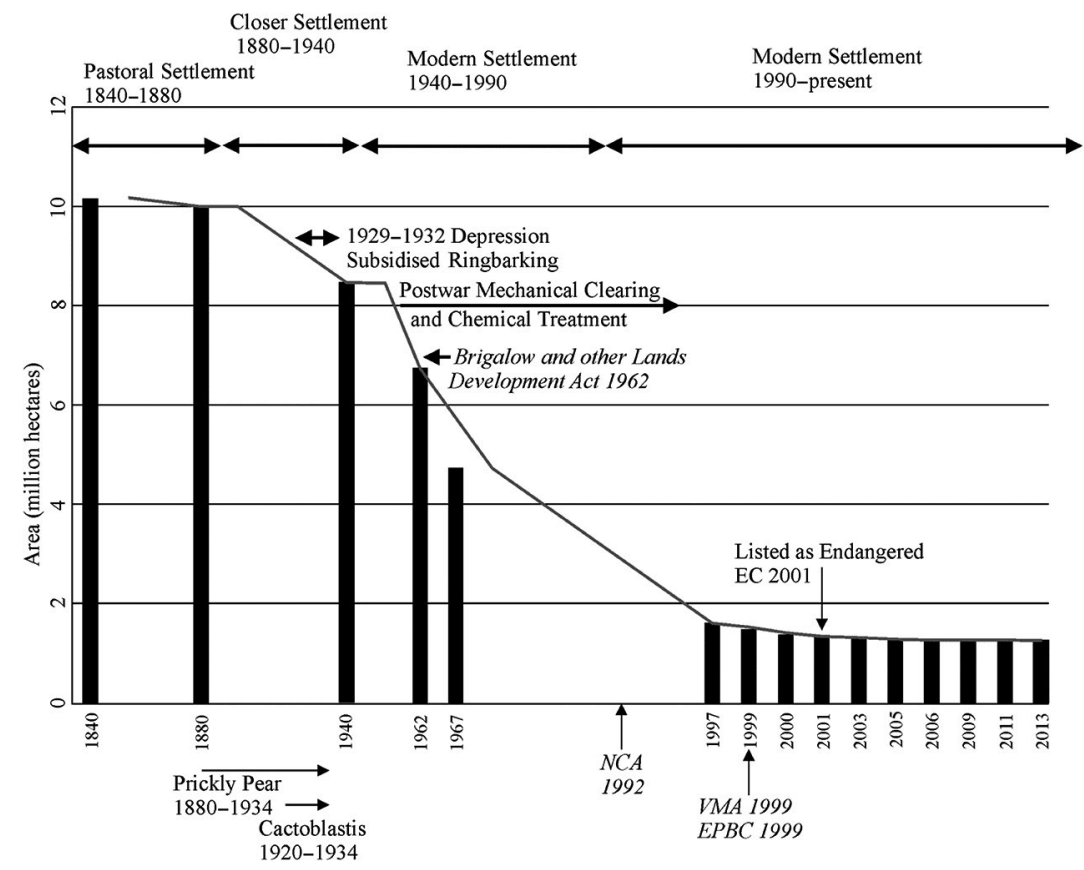

Figure 8.1: Diagram illustrating the decline in extent of the brigalow broad vegetation group.

Source: Neldner et al. (2017). Annotated with social, economic and legislative drivers and extent figures derived from Seabrook et al. (2006). Pre-clearing and remnant brigalow extent 1997-2013 from Accad \& Neldner (2015).

Figure 8.1 summarises the range of social, economic, legislative and environmental factors described in Seabrook et al. (2006) that have affected the brigalow ecological community. Since European settlement, 
the brigalow ecological community has declined from 10.2 million hectares (5.9 per cent of Queensland) to be an EPBC-listed Endangered Ecological Community of only 1.3 million hectares in 2011 (Neldner et al., 2017). A recovery plan developed in 2001 included protection of the remnant patches in the conservation estate, protection of regrowth older than 15 years under the EPBC (and sometimes the VMA under various conditions) and the potential enhancement of some regrowth through offsets. The remaining brigalow is likely to be further fragmented via infrastructure for coal seam gas extraction and processing; it is also threatened by the encroachment of non-native species, such as buffel grass, that can lead to fire regimes that degrade the community; for example, at Mazeppa National Park (Butler \& Fairfax, 2003). However, eucalypt and brigalow woodlands are the most likely to benefit from reforestation planting because of the relative cost effectiveness of carbon sequestration in those systems (Carwardine et al., 2015).

\section{Recommendations}

1. The impact of land use change on biodiversity is complicated and includes direct and indirect impacts. Continued systematic monitoring of both flora and fauna at both the landscape scale (including changes in extent and condition) and site scale (multiple attribute) is required to understand and manage these impacts.

2. A number of approaches (both legislative- and incentive-based) are required to ensure that what biodiversity remains in fragmented (e.g. brigalow) and even largely unaltered landscapes (e.g. savannas) is retained and sustainably managed.

\section{References}

Accad, A. \& Neldner, V. J. (2015). Remnant vegetation in Queensland: Analysis of pre-clearing, remnant 1997-1999-2000-2001-2003-20052007-2009-2011-2013 regional ecosystem information. Brisbane, QLD: Queensland Herbarium, Department of Science, Information Technology and Innovation. 
Accad, A., Neldner, V. J., Wilson, B. A. \& Niehus, R. E. (2001). Remnant vegetation in Queensland: Analysis of pre-clearing, remnant 1997-1999 regional ecosystem information. Brisbane, QLD: Queensland Herbarium, Environmental Protection Agency.

Bowen, M. E., McAlpine, C. A., House, A. P. N. \& Smith, G. C. (2007). Regrowth forests on abandoned agricultural land: A review of their habitat values for recovering forest fauna. Biological Conservation 140, 273-96. www.sciencedirect.com/science/article/pii/ S0006320707003308

Butler, D. W. \& Fairfax, R. J. (2003). Buffel grass and fire in a gidgee and brigalow woodland: A case study from central Queensland. Ecological Management and Restoration 4, 120-25. doi.org/10.1046/j.14428903.2003.00146.x/abstract

Carwardine, J., Hawkins, C., Polglase, P., Possingham, P., Reeson, A., Renwick, A. R., ... Martin, T. (2015). Spatial priorities for restoring biodiverse carbon forests. Bioscience 65(4), 372-82. doi.org/10.1093/ biosci/biv008

Cogger, H. G., Ford, H. A., Johnson, C. N., Holman, J. \& Butler, D. (2003). Impacts of land clearing on Australian wildlife in Queensland. Brisbane, QLD: World Wildlife Fund Australia.

Covacevich, J. A. (1995). Realities in the biodiversity Holy Grail: Prospects for reptiles of Queensland's brigalow biogeographic region. Proceedings of the Royal Society of Queensland 106, 1-9.

Dwyer, J. M., Fensham, R. J., Butler D. W. \& Buckley, Y. M. (2009). Carbon for conservation: Assessing the potential for win-win investment in an extensive Australian regrowth ecosystem. Agriculture Ecosystems and Environment 134, 1-7. doi.org/xml/10.2307/25741351

Eyre, T. J., Fisher, A., Hunt, L. P. \& Kutt, A. S. (2011). Measure it to better manage it: A biodiversity monitoring framework for the Australian rangelands. The Rangeland Journal 33, 239-53. doi.org/10.1071/ RJ10071

Fensham, R. J. \& Guymer, G. P. (2009). Carbon accumulation through ecosystems recovery. Environmental Science and Policy 12, 367-72. doi.org/10.1016/j.envsci.2008.12.002 
Fensham, R. J., Wang, J. \& Kilgour, C. (2015). The relative impacts of grazing, fire and invasion by buffel grass (Cenchrus ciliaris) on the floristic composition of a rangeland savanna ecosystem. The Rangeland Journal 37, 227-37. doi.org/10.1071/RJ14097

Geddes, L. S., Lunt, I. D., Smallbone, L. T. \& Morgan, J. W. (2011). Old field colonization by native trees and shrubs following land use change: Could this be Victoria's largest example of landscape recovery? Ecological Management and Restoration 12, 31-6. doi.org/10.1111/ j.1442-8903.2011.00570.x/abstract

Graetz, R. D., Wilson, M. A. \& Campbell, S. K. (1995). Landcover disturbance over the Australian continent - a contemporary assessment (Biodiversity Series, no. 7). Canberra, ACT: Department of the Environment, Sport and Territories.

Haddad, N. M., Brudvig, L. A. \& Clobert, J. (2015). Habitat fragmentation and its lasting impact on Earth's ecosystems. Science Advances 1(2). doi.org/10.1126/sciadv.1500052

International Union for Conservation of Nature. (2012). IUCN red list categories and criteria: Version 3.1 (2nd ed.). Cambridge, UK: IUCN.

Lindenmayer, D. B., Burns, E. L. \& Tennant, P. (2015). Contemplating the future: Acting now on long-term monitoring to answer 2050's questions. Austral Ecology 40, 213-24. doi.org/10.1111/aec.12207

MacNally, R., Kutt, A. S., Eyre, T. J., Perry, J. J., Vanderduys. E. P., Mathieson, M. ... Thomson, J. R. (2014). The hegemony of the 'despots': The control of avifaunas over vast continental areas. Diversity and Distributions 20, 1071-83. doi.org/10.1111/ddi.12211

Maron, M., Bowen, M., Fuller, R. A., Smith, G. C., Eyre, T. J., Mathieson, M., ... McAlpine, C. A. (2012). Spurious thresholds in the relationship between species richness and vegetation cover. Global Ecology and Biogeography 21, 682-92. doi.org/10.1111/j.14668238.2011.00706.x

McAlpine, C. A., Fensham, R. J. \& Temple-Smith, D. E. (2002). Biodiversity conservation and vegetation clearing in Queensland: Principles and thresholds. The Rangeland Journal 24, 36-55. doi.org/ 10.1071/RJ02002 
Morgan, G. (2001). Landscape health in Australia. A rapid assessment of the relative condition of Australia's bioregions and subregions. Canberra, ACT: Environment Australia and National Land and Water Resources Audit.

Munro, N. T., Fischer, J., Wood, J. \& Lindenmayer, D. B. (2009). Revegetation in agricultural areas: The development of structural complexity and floristic diversity. Ecological Applications 19(5), 1197.

Neldner, V.J., Niehus, R.E., Wilson, B.A., McDonald, W.J.F., Ford, A.J. \& Accad, A. (2017). The Vegetation of Queensland. Descriptions of Broad Vegetation Groups. Version 3.0. Queensland Herbarium, Department of Science, Information Technology and Innovation, Brisbane. Retrieved from publications.qld.gov.au/dataset/redd/resource/78209e 74-c7f2-4589-90c1-c33188359086

Newsome, T. M., Ballard, G., Crowther, M. S., Dellinger, J. A., Fleming, P. J. S., Glen, A. S., ... Dickman, C. R. (2015). Resolving the value of the dingo in ecological restoration. Restoration Ecology 23, 201-08. doi.org/10.1111/rec.12186

Seabrook, L., McAlpine, C. \& Fensham, R. (2006). Cattle, crops and clearing: Regional drivers of landscape change in the Brigalow Belt, Queensland, Australia, 1840-2004. Landscape and Urban Planning 78, 373-85. doi.org/10.1016/j.landurbplan.2005.11.007

Taylor, M. F. J., Eber, S. C. \& Toni, P. (2014). Changing land use to save Australian wildlife. Sydney, NSW: World Wildlife Fund Australia.

Thackway, R. \& Lesslie, R. (2006). Reporting vegetation condition using the vegetation assets, states and transitions (VAST) framework. Ecological Management and Restoration 7, S53-S62. doi.org/10.1111/ j.1442-8903.2006.00292.x

Woinarski, J. C. Z., Burbidge, A. A. \& Harrison, P. L. (2015). Ongoing unravelling of a continental fauna: Decline and extinction of Australian mammals since European settlement. PNAS 112(15), 4531-40. doi.org/10.1073/pnas.1417301112 
This text is taken from Land Use in Australia: Past, Present and Future, edited by Richard Thackway, published 2018 by ANU eView, The Australian National University, Canberra, Australia.

doi.org/10.22459/LUA.02.2018.08 